\title{
Alosetron was effective and safe for relieving abdominal symptoms in women with irritable bowel syndrome
}

\author{
Camilleri M, Northcutt AR, Kong S, et al. Efficacy and safety of alosetron in women with irritable bowel syndrome: a \\ randomised, placebo-controlled trial. Lancet 2000 Mar 25;355:1035-40.
}

\section{QUESTION: What is the effectiveness and safety of alosetron in women with irritable bowel syndrome (IBS)?}

\section{Design}

Randomised (allocation concealed*), blinded (clinicians, patients, outcome assessors, and statisticians),* placebo controlled trial for 12 weeks with 1 month follow up.

\section{Setting}

119 centres in the US.

\section{Patients}

647 women $\geqslant 18$ years of age (mean age $46 \mathrm{y}, 93 \%$ white) who had IBS for $\geqslant 6$ months, had normal colonic anatomy, were diarrhoea predominant or had alternating bowel patterns (diarrhoea and constipation), had a mean daily abdominal pain and discomfort score between 1.0 and 3.3 on a 5 point scale $(0=$ none to $4=$ severe $)$, and a mean daily stool consistency score $\geqslant 2.5$ on a 5 point scale $(1=$ very hard to $5=$ watery). Exclusion criteria were constipation predominant IBS; pregnancy, breast feeding, or potential for childbearing; unstable medical or other gastrointestinal disorder; major psychiatric disorder; substance abuse in the previous 2 years; abnormal aspartate aminotransferase, alanine aminotransferase, or serum creatinine concentrations; hyperthyroidism or hypothyroidism; non-skin malignancy in the previous 5 years; investigational drug use 30 days before study; or use of specified drugs. Follow up was $80 \%$.

\section{Intervention}

Women were allocated to twice daily oral alosetron, 1 $m g(n=324)$, or placebo $(n=323)$ for 12 weeks. Study drugs were taken before meals.

\section{Main outcome measures}

Adequate relief of abdominal pain and discomfort; improvements in urgency, stool frequency, and stool consistency; and adverse events.

\begin{abstract}
Main results
Analysis was by intention to treat. Alosetron had a higher rate of achieving adequate relief of abdominal pain and discomfort $\{\mathrm{p}=0.001\} \uparrow$ (table) and decreased urgency, stool frequency, and stool consistency (ie, increased stool firmness $)(\mathrm{p}<0.001)$ than did placebo. Alosetron was associated with a higher risk for constipation than was placebo $\{\mathrm{p}<0.001\} \nmid$ (table), but groups did not differ in the rate of reporting $\geqslant 1$ adverse events $\{\mathrm{p}=0.07\} \dagger$.
\end{abstract}

\section{Conclusion}

Alosetron was effective and well tolerated in relieving abdominal pain and discomfort in women with irritable bowel syndrome.

*See glossary.

$\uparrow \mathrm{p}$ Values calculated from data in article.

Alosetron v placebo in women who have had irritable bowel syndrome $>3$ months $\$$

\begin{tabular}{|c|c|c|c|c|}
\hline Outcomes at 1 month follow up & Alosetron & Placebo & RBI $(95 \%$ CI) & NNT (Cl) \\
\hline Relief of abdominal symptoms & $41 \%$ & $29 \%$ & $41 \%$ (14 to 75$)$ & 8 (5 to 22$)$ \\
\hline & & & RRI $(95 \%$ Cl) & NNH (CI) \\
\hline Constipation & $30 \%$ & $3 \%$ & $854 \%$ (415 to 1685 ) & 4 (3 to 5$)$ \\
\hline
\end{tabular}

¥Abbreviations defined in glossary; RBI, RRI, NNT, and $\mathrm{Cl}$ calculated from data in article.

\section{COMMENTARY — continued from previous page}

with the US Food and Drug Administration, prompted by postmarketing reports of serious adverse effects, including severe constipation, ischaemic colitis, and death (unproved association).

IBS is a chronic disorder with frequent relapses and substantial morbidity, although no mortality is caused by the disease itself. Therefore, the decision to initiate long term pharmacotherapy should not be taken lightly. Only further trials and postmarketing surveillance strategies will determine whether the class of drugs represented by the ill fated alosetron will be safe and better than smooth muscle relaxants and loperamide and their combination with other interventions.

As investigators more accurately classify various subgroups of IBS, understand their unique pathophysiologies, and study the effects of the emerging therapeutic agents, targeted therapeutic interventions will become better defined. A supportive physicianpatient relationship is necessary regardless of the therapeutic regimen. The availability of treatments that selectively antagonise the factors responsible for IBS symptoms adds a scientific dimension to the management of a very common, poorly understood, and challenging disorder.

\section{Arvey I Rogers, MD \\ Vikas Khurana, MD University of Miami, Miami, Florida, USA}

1 Drossman DA, Whitehead WE, Camilleri M. Irritable bowel syndrome: a technical review for practice guideline development. Gastroenterology 1997;112:2120-37.

2 De Ponti F, Malagelada JR. Functional gut disorders: from motility to sensitivity disorders. A review of current and investigational drugs for their management. Pharmacol Ther 1998;80:49-88.

\author{
Source of funding: \\ Glaxo Wellcome \\ Research and \\ Development. \\ For correspondence: \\ Dr A W Mangel, \\ Gastroenterology \\ Clinical Development, \\ Glaxo Wellcome, \\ Research Triangle \\ Park, NC 27709, USA. \\ Fax +1919483 \\ 8614.
}

